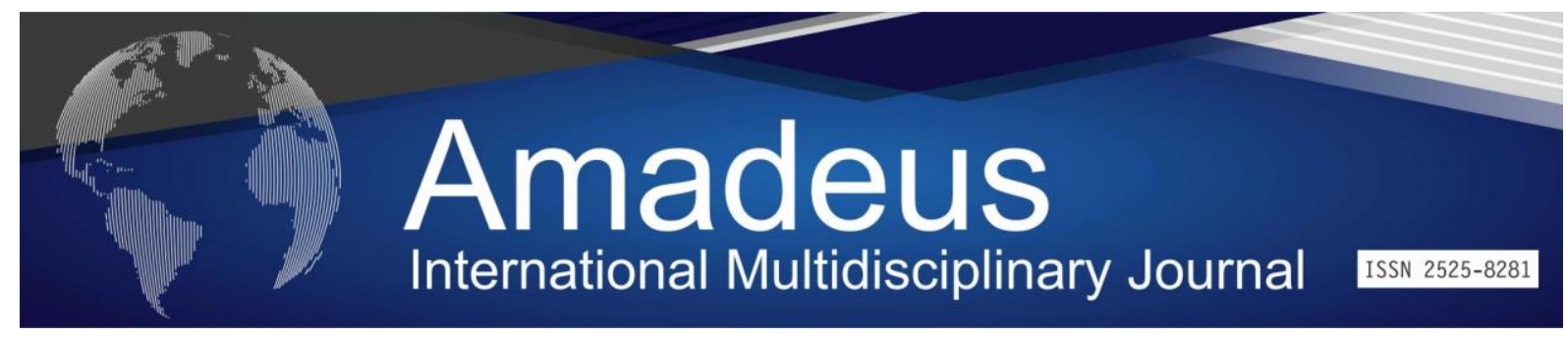

DOI: 10.14295/aimj.v5i9.112

\title{
Approach to Women's Health in Social Vulnerability Situations: An Integrative Review
}

Lina Maria Vidal Romão ${ }^{1}$ José Leonardo Gomes Coelho²; Pedro Walisson Gomes Feitosa $^{3}$

Karine Silva Melo ${ }^{4}$ Carmelita Maria Silva Sousa, Thiago Adolfo Sobreira Miranda $^{6}$

Emanuela Machado Silva Saraiva ${ }^{7}$ Samya de Araújo Neves ${ }^{8}$ Willma José de Santana

\begin{abstract}
Gender violence consists of a rising world phenomenon that wounds human dignity by countering equality among peoples, with fatal outcomes occurring in all social classes and preferably within the domestic sphere. Corresponding to the male population the exercise of domination by physical and psychological force usually against their partner. The purpose of this study was to understand the perception of the women assisted in the Basic Health Units on gender violence, as well as to know what the BHUs are / can do to prevent it in its territoriality. For this, an integrative review of the literature was carried out, where articles were selected in the databases Scielo, Pubmed and Lilacs, according to the descriptors Violence, woman, public health, gender. Inclusion criteria were articles that were consistent with the theme and were available in full between 2015 and 2018, in English and Portuguese, and excluding articles that did not meet the pre-established criteria. A total of 32 articles were found, in which 10 articles were selected. In which one can conclude the great fragility of the woman affected by violence by the fact that the companions are the main aggressors, involving extremely subjective factors, such as love, affection, the family built next to this man, these being the reasons for the challenge of breaking with violence and that the role of the UBS in relation to this type of violence still has a deficiency due to the little clarification that they have about the possibilities of conduct on the subject.
\end{abstract}

Keywords: Violence. Woman. Public health. Genre.

\footnotetext{
${ }^{1}$ Master's student in Public Policy at Universidade Athenas College. Email: linamariaromao@ hotmail.com;

${ }^{2}$ Pharmacy Student at the Centro Universitário de Juazeiro do Norte - UNIJUAZEIRO.

Email: leonardo-coelho-10@hotmail.com;

${ }^{3}$ Medical Student at Universidade Federal do Cariri. Email: gomesfeitoa.walisson@outlook.com;

4 Pharmacy Student at the Centro Universitário de Juazeiro do Norte - UNIJUAZEIRO. Email: kkarinemelo@hotmail.com;

${ }^{5}$ Master's student in Public Policy at Universidade Athenas College. Email: carmelitasilva11 @ hotmail.com;

${ }^{6}$ Master in Molecular Bioprospecting at Universidade Regional do Cariri, Professor at Centro Universitário de Juazeiro do Norte - UNIJUAZEIRO. Email: thiagoadolfosm@hotmail.com;

${ }^{7}$ Master in Health Sciences at Centro Universitário Saúde ABC - CUSABC and Professor at Centro Universitário de Juazeiro do Norte - UNIJUAZEIRO. Email: emanuelams@ hotmail.com;

${ }^{8} \mathrm{PhD}$ in Biochemistry from the Universidade Federal do Ceará, Professor at Centro Universitário de Juazeiro do Norte

- UNIJUAZEIRO. Email: samya.neves@ fjn.edu.br;

${ }^{9}$ Post Doctoral Student in Health Sciences - FMABC, PhD in Biological Sciences at UFPE and Professor at Centro Universitário de Juazeiro do Norte - UNIJUAZEIRO and Faculty of Technology - FATEC - CARIRI. Email: wjsantana@hotmail.com.
} 


\section{Abordagem à Saúde da Mulher em Situação de Vulnerabilidade Social: Uma Revisão Integrativa}

\begin{abstract}
Resumo: A violência de gênero consiste em um fenômeno mundial em ascensão que fere a dignidade humana contrariando a igualdade entre os povos, com desfechos fatais ocorrendo em todas as classes sociais e preferencialmente no âmbito doméstico. Correspondendo à população masculina o exercício da dominação pela força física e psicológica geralmente contra sua parceira. Objetivou ao realizar esse estudo compreender a percepção das mulheres atendidas nas Unidades Básicas de Saúde sobre a violência de gênero, bem como conhecer o que as UBS fazem ou podem fazer para a prevenção desta na sua territorialidade. Para isto realizou-se uma revisão integrativa da literatura, onde foram selecionados artigos nas bases de dados Scielo, Pubmed e Lilacs, de acordo com os descritores: Violência, mulher, saúde pública, gênero. Como Critérios de inclusão utilizou-se artigos coerentes com o tema e que estavam disponíveis na íntegra entre os anos de 2015 a 2018, nos idiomas inglês e português, e de exclusão os artigos que não atendessem aos critérios pré-estabelecidos. Foram encontrados ao todo 32 artigos, nos quais foram selecionados 10 artigos. No qual pode-se concluir a grande fragilidade da mulher acometida pela violência pelo fato dos companheiros serem os principais agressores, envolvendo então fatores extremamente subjetivos, como o amor, a afetividade, a família construída ao lado deste homem, sendo estas as razões do desafio de romper com a violência e que o papel das UBS a respeito desse tipo de violência ainda possui deficiência devido ao pouco esclarecimento que se têm sobre as possibilidades de condutas a respeito do assunto.
\end{abstract}

Palavras-chaves: Violência. Mulher. Saúde pública. Gênero.

\section{Introdução}

O conceito de vulnerabilidade social vem, ao longo dos anos, ganhando cada vez mais amplitude e repercussão perante as organizações sócio-políticas mundiais, dentre elas as voltadas à saúde pública. A concepção desse termo denota não estritamente a ausência ou precariedade no acesso à renda, mas atrela também as fragilidades de vínculos afetivorelacionais e desigualdade de acesso a bens e serviços públicos (Carmo e Guizardi, 2018). Nesta gama composta pelos mais diversos grupos sociais e exposta a diferentes dilemas, julgamos necessário, no presente artigo, buscar um olhar sobre a questão da violência de gênero relacionada às mulheres nessas condições de vulnerabilidade, buscando entender os pontos que estas trazem em comum em suas histórias, bem como o que as diferencia dentro de um contexto geral. 
A violência de gênero pode ser conceituada como qualquer ato que resulta ou venha a resultar em dano ou sofrimento, seja este físico, sexual ou psicológico à mulher, incluindo ameaças de tais atos, coerção ou privação arbitrária de liberdade em público ou em caráter privado, bem como castigos, maus tratos, pornografia, agressão sexual e incesto (Kronbauer e Meneguel, 2005). Comparando-se, portanto, a violência sofrida por homens e mulheres, observamos que, enquanto a maioria dos homens são vítimas de violência na esfera pública, a violência sofrida pelas mulheres se dá com maior frequência no ambiente doméstico, perpetrada principalmente pelo parceiro ou ex-parceiro, sob condições severas e repetitivas (Terra; D’oliveira; Schraiber, 2015).

É necessário notarmos que, dentro do grande grupo de mulheres submetidas aos atos violentos nas suas mais diversas categorias, encontramos semelhanças, não de forma aleatória, mas que refletem um padrão perpetuado ao longo dos anos e imposto pela sociedade, em sua grande maioria machista e patriarcal. Historicamente as mulheres tem se situado em posições subalternas na sociedade, em função de uma diferenciação dos sexos sociais, alimentada pela divisão sexual do trabalho e estruturada na valorização das atividades ditas masculinas, o que pode resultar em um menor acesso aos bens e serviços por parte das mulheres (Duarte et al, 2015).

É nesse âmbito que enquadramos a grande maioria das mulheres vítimas de violência de gênero entre as pertencentes às classes menos favorecidas (Kronbauer e Meneguel, 2005). Em relação ao estado civil, observa-se que as mulheres vítimas de violência apresentaram uma maior proporção quando se diziam compartilhar uma união estável $(48,2 \%)$. Já com relação à raça/cor, observa-se, em sua maioria, mulheres pardas $(62,9 \%)$, tendo como ocupação atividades do lar (46,3\%) com renda mensal de até dois salários mínimos (70,4\%) (Albuquerque et al, 2013).

A violência baseada em gênero possui um alto índice de morbi-mortalidade, constituindo um caso de saúde pública grave, considerando os prejuízos para a saúde da mulher e suas consequências para sua vida social, o qual ocorre no ambiente doméstico e tem como principal agressor o companheiro, sendo denominada de VPI - violência por parceiro íntimo (Barros et al, 2016).

Vendo sob a ótica do quão intrínseco se encontram os casos de violência de gênero na nossa sociedade, ressaltamos a importância da saúde pública no tocante a este tema. Os profissionais de saúde foram identificados como peças-chave para o reconhecimento dos casos de violência, já que as mulheres que a vivenciam, tendem a procurar os serviços, em 
decorrência das consequências físicas e psicológicas que sofrem. Estes profissionais, portanto, devem estar qualificados para identificar as situações de violência contra as mulheres, bem como para construir com elas um posicionamento crítico reflexivo sobre as desigualdades de gênero legitimadas na sociedade em que vivemos (Duarte et al, 2015).

Este estudo tem por objetivo realizar uma revisão integrativa da literatura dos últimos cinco anos quanto à abordagem da saúde das mulheres em situação de vulnerabilidade social.

\section{Metodologia}

Para o desenvolvimento deste estudo, realizou-se uma revisão integrativa da literatura. Propôs-se analisar as questões que envolvem a assistência à saúde da mulher que vive em situação de vulnerabilidade social, seus desafios e a visão dessas mulheres quanto à assistência recebida.

Ao total foram encontrados 32 artigos, após a leitura na íntegra e tendo-se verificado sua correlação com o tema selecionou-se 10 artigos, disponíveis nas bases de dados Scielo, Pubmed e Lilacs. Onde se utilizou como descritores: Violência; Vulnerabilidade; mulher; saúde pública e gênero.

Como critérios de inclusão, optou-se por artigos que abrangessem a temática vulnerabilidade social de mulheres e suas repercussões, que se encontravam entre o período de 2015 a 2018, nos idiomas inglês e português. E como critérios de exclusão artigos não disponíveis na íntegra ou que fugissem no tema proposto.

\section{Resultados e Discussão}

De uma forma geral é possível perceber que a violência contra a mulher vem sendo cada vez mais frequente na sociedade atual e que, se comparado aos tempos mais remotos, isso vem causando uma revolta em grande escala. E diante disso, é notória a necessidade que esse grupo tem de maior punição aos seus agressores como forma de justiça ao crime praticado contra tais pessoas. 
Quadro 1. Síntese dos artigos selecionados

\begin{tabular}{|c|c|c|c|c|}
\hline $\begin{array}{l}\text { Autor/ } \\
\text { Ano/ } \\
\text { Base de } \\
\text { Dados } \\
\end{array}$ & Objetivo & Metodologia & Resultado Primário & Conclusão \\
\hline $\begin{array}{l}\text { Oliveira et } \\
\text { al./ (2015) / } \\
\text { SCIELO }\end{array}$ & $\begin{array}{l}\text { Compreender os limites e } \\
\text { as possibilidades } \\
\text { avaliativas da Estratégia } \\
\text { Saúde da Família no que } \\
\text { tange ao reconhecimento } \\
\text { de necessidades em } \\
\text { saúde de mulheres que } \\
\text { vivenciam violência. }\end{array}$ & $\begin{array}{l}\text { Os dados foram coletados por } \\
\text { entrevistas com profissionais } \\
\text { de saúde e mulheres usuárias } \\
\text { de um serviço de saúde e } \\
\text { analisados a partir do método } \\
\text { de análise do discurso. }\end{array}$ & $\begin{array}{l}\text { O encontro entre os discursos de } \\
\text { mulheres usuárias e de profissionais } \\
\text { do serviço de saúde revelaram como } \\
\text { interface necessidades propriamente } \\
\text { humanas, a exemplo da autonomia e } \\
\text { do vínculo. }\end{array}$ & $\begin{array}{l}\text { Destaca-se a } \\
\text { perspectiva de gênero } \\
\text { enquanto ferramenta } \\
\text { que deve ser agregada } \\
\text { ao cotidiano das } \\
\text { práticas profissionais } \\
\text { em saúde para } \\
\text { confirmar ou negar o } \\
\text { caráter transformador } \\
\text { da assistência em } \\
\text { vigor no que concerne } \\
\text { ao reconhecimento e } \\
\text { enfrentamento das } \\
\text { necessidades em saúde } \\
\text { das mulheres. }\end{array}$ \\
\hline $\begin{array}{l}\text { Silva et al./ } \\
(2015) \quad / \\
\text { REDALCY }\end{array}$ & $\begin{array}{l}\text { Buscou-se conhecer e } \\
\text { analisar as concepções de } \\
\text { profissionais das equipes } \\
\text { de saúde da Família em } \\
\text { relação à violência contra } \\
\text { a mulher e à prática } \\
\text { assistencial. }\end{array}$ & $\begin{array}{l}\text { Participaram trinta } \\
\text { profissionais, em oito } \\
\text { reuniões, que se constituíram } \\
\text { em um processo de reflexão } \\
\text { e aprendizagem, nos meses } \\
\text { de setembro a dezembro de } \\
2012 .\end{array}$ & $\begin{array}{l}\text { Os profissionais } \\
\text { compreendem que a violência } \\
\text { contra a mulher existe devido à } \\
\text { hierarquia nas relações entre } \\
\text { homens e mulheres, que confere } \\
\text { mais } \\
\text { poder ao homem, situação que o } \\
\text { legitima a praticar a violência. }\end{array}$ & $\begin{array}{l}\text { A prática assistencial } \\
\text { parte de uma } \\
\text { concepção biológica } \\
\text { do problema } \\
\text { com tendência à } \\
\text { social. Os cuidados } \\
\text { direcionam-se ao } \\
\text { tratamento da lesão } \\
\text { Física, escuta, } \\
\text { orientação à denúncia } \\
\text { e encaminhamento a } \\
\text { setores especializados } \\
\text { de saúde e assistência } \\
\text { social. }\end{array}$ \\
\hline $\begin{array}{l}\text { Vieira et al. } \\
/(2017) \\
\text { SCIELO }\end{array}$ & $\begin{array}{l}\text { Objetivou-se conhecer } \\
\text { como profissionais } \\
\text { envolvidos com atenção } \\
\text { às mulheres em situação } \\
\text { de violência em uma } \\
\text { rede intersetorial } \\
\text { percebem os } \\
\text { atendimentos que fazem. }\end{array}$ & $\begin{array}{l}\text { Foram realizadas trinta } \\
\text { entrevistas com profissionais } \\
\text { de serviços dos setores de } \\
\text { saúde, assistência social } \\
\text { (AS), segurança pública (SP) } \\
\text { e judiciário de uma cidade de } \\
\text { porte médio. }\end{array}$ & $\begin{array}{l}\text { Há percepções fragmentadas e } \\
\text { estereotipadas e necessidade de } \\
\text { aprimorar a infraestrutura existente, } \\
\text { preparar e amparar os profissionais } \\
\text { para humanizar os atendimentos. }\end{array}$ & $\begin{array}{lr}\text { Criar } & \text { serviços } \\
\text { específicos e investir } \\
\text { em prevenção é } \\
\text { fundamental, pois } \\
\text { existe r um } \\
\text { descompasso entre } \\
\text { intenção política de } \\
\text { enfrentamento à } \\
\text { violência e realidade } \\
\text { estudada. }\end{array}$ \\
\hline $\begin{array}{l}\text { Souza et al. } \\
/(2018) \\
\text { LILACS }\end{array}$ & $\begin{array}{l}\text { O estudo investigou as } \\
\text { concepções e práticas de } \\
\text { profissionais de saúde } \\
\text { acerca do fenômeno da } \\
\text { violência contra mulher. }\end{array}$ & $\begin{array}{l}\text { Foi realizado estudo } \\
\text { qualitativo, cuja amostra foi } \\
\text { composta por } 9 \text { participantes } \\
\text { (três médicas, três } \\
\text { enfermeiras e três psicólogas) } \\
\text { que atendiam mulheres nas } \\
\text { unidades públicas de saúde } \\
\text { de Jataí/GO. Para a obtenção } \\
\text { de dados, foi utilizada } \\
\text { entrevista individual e } \\
\text { semiestruturada. }\end{array}$ & $\begin{array}{l}\text { Os discursos apontaram que grande } \\
\text { parte das mulheres que chegam às } \\
\text { unidades de saúde pública para } \\
\text { procurar ajuda por terem sofrido } \\
\text { violência física, geralmente, já } \\
\text { passou por outros tipos de } \\
\text { violências, como a psicológica e } \\
\text { sexual. }\end{array}$ & $\begin{array}{l}\text { Averiguou-se } \\
\text { fragilidades teórico- } \\
\text { metodológicas das } \\
\text { profissionais sobre a } \\
\text { temática da violência } \\
\text { contra a mulher, bem } \\
\text { como dificuldades nas } \\
\text { ações de prevenção, } \\
\text { acolhimento } \\
\text { notificação } \\
\text { serviços de saúde. dos } \\
\end{array}$ \\
\hline $\begin{array}{l}\text { Santos et } \\
\text { al. / (2018) } \\
\text { / LILACS }\end{array}$ & $\begin{array}{lr}\text { Compreender } & \text { as } \\
\text { representações sociais de } & \\
\text { profissionais da Atenção } & \text { à } \\
\text { Primária } & \text { aúde sobre violência } \\
\text { contra a } & \\
\text { mulher perpetrada por } \\
\text { parceiro íntimo. }\end{array}$ & $\begin{array}{lr}\text { Pesquisa } & \text { qualitativa com } 0 \\
\text { enfoque nas Representações } \\
\text { Sociais, analisado pela } \\
\text { Análise } & \text { Estrutural } \\
\text { da Narração. } & \text { Foram } \\
\text { realizados oito grupos focais, } \\
\text { o número de participantes } \\
\text { variou de } 8 \text { a } 12 \text {, totalizando }\end{array}$ & $\begin{array}{l}\text { Emergiram duas categorias: } 1 \text {. Do } \\
\text { ditado popular à banalização } \\
\text { da violência conjugal } \\
\text { contra mulheres, identificando-se os } \\
\text { núcleos de sentido: "não se interfere } \\
\text { em briga de casal"; "naturalização } \\
\text { da violência legitimada } \\
\text { representações nociais. }\end{array}$ & $\begin{array}{l}\text { O estudo demonstrou } \\
\text { que a violência contra } \\
\text { as mulheres é } \\
\text { legitimada, aceita e } \\
\text { tolerada nas falas dos } \\
\text { participantes, como } \\
\text { algo imputado/inerente } \\
\text { à mulher. }\end{array}$ \\
\hline
\end{tabular}




\begin{tabular}{|c|c|c|c|c|}
\hline & & 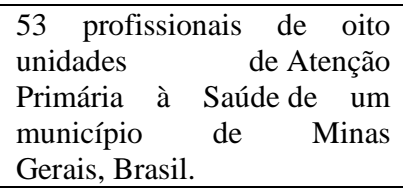 & $\begin{array}{l}\text { Representações sociais numa } \\
\text { perspectiva de gênero, decorrida dos } \\
\text { núcleos de sentido: "representações } \\
\text { associadas aos papeis de gênero"; } \\
\text { "imputação de culpa à mulher". }\end{array}$ & \\
\hline $\begin{array}{l}\text { Souza et al. } \\
/(2018) \\
\text { LILACS }\end{array}$ & $\begin{array}{l}\text { Identificar as principais } \\
\text { dificuldades, incluindo } \\
\text { conflitos éticos, } \\
\text { encontradas } \\
\text { pelos médicos na } \\
\text { abordagem } \\
\text { de pacientes vítimas } \\
\text { desse tipo de violência. }\end{array}$ & $\begin{array}{l}\text { Os obstáculos elementares } \\
\text { foram agrupados em três } \\
\text { grandes eixos: questões } \\
\text { relacionadas ao profissional } \\
\text { de saúde; estrutura do } \\
\text { sistema de saúde; e aspectos } \\
\text { das vítimas de violência. }\end{array}$ & $\begin{array}{l}\text { A análise dos artigos permitiu } \\
\text { definir três eixos principais com } \\
\text { relação aos obstáculos encontrados } \\
\text { pelos profissionais no atendimento } \\
\text { de mulheres em situação de } \\
\text { violência. O primeiro deles versa } \\
\text { sobre profissionais de saúde: } \\
\text { percepções pessoais, atitudes, } \\
\text { formação e capacitação, barreiras } \\
\text { pessoais e sentimentos gerados pela } \\
\text { violência. O segundo aborda a } \\
\text { situação do sistema de saúde e sua } \\
\text { articulação com demais serviços } \\
\text { disponíveis para tratar e acolher as } \\
\text { mulheres em situação de violência. } \\
\text { Por fim, o terceiro eixo contém } \\
\text { aspectos relacionados às usuárias do } \\
\text { sistema de saúde vítimas de } \\
\text { violência. }\end{array}$ & $\begin{array}{l}\text { Concluiu-se que o } \\
\text { maior entrave advém } \\
\text { do próprio profissional } \\
\text { de saúde e envolve } \\
\text { fatores que variam } \\
\text { desde formação } \\
\text { inadequada até a } \\
\text { ocorrência de conflitos } \\
\text { morais e éticos que } \\
\text { culminam na } \\
\text { culpabilização a } \\
\text { responsabilização das } \\
\text { vítimas pela situação } \\
\text { de violência em que se } \\
\text { encontram. }\end{array}$ \\
\hline $\begin{array}{l}\text { Martins et } \\
\text { al. / (2018) } \\
\text { / LILACS }\end{array}$ & $\begin{array}{lr}\text { Avaliar } & \text { os } \\
\text { conhecimentos r e } \\
\text { condutas de profissionais } \\
\text { de unidades da Estratégia } \\
\text { Saúde da } \\
\text { Família frente à violência } \\
\text { de gênero. }\end{array}$ & $\begin{array}{l}\text { Estudo descritivo, realizado } \\
\text { com } 53 \text { profissionais de sete } \\
\text { unidades de Estratégia Saúde } \\
\text { da Família no período de } \\
\text { março a julho de } 2015 \text {. Os } \\
\text { dados foram coletados por } \\
\text { meio de instrumento } \\
\text { autopreenchido e analisados } \\
\text { no software Excel } 2007 \text {. }\end{array}$ & $\begin{array}{l}\text { Observou-se que } \\
\text { o conhecimento dos profissionais } \\
\text { sobre as definições, epidemiologia e } \\
\text { manejo da violência variou de } \\
\text { razoável a ótimo, apesar de } \\
\text { conhecerem pouco sobre } \\
\text { a prevalência de violência durante o } \\
\text { período gestacional. Quanto às } \\
\text { condutas, evidenciou-se dificuldade } \\
\text { em questionar as mulheres sobre } \\
\text { a violência e sua notificação. Os } \\
\text { profissionais com } \\
\text { menor tempo de assistência e que } \\
\text { receberam capacitação apresentaram } \\
\text { condutas mais adequadas. }\end{array}$ & $\begin{array}{l}\text { Sugere-se a realização } \\
\text { de ações educativas } \\
\text { visando fornecer } \\
\text { subsídios para a } \\
\text { atuação } \\
\text { profissionais frente aos } \\
\text { casos de violência de } \\
\text { gênero. }\end{array}$ \\
\hline $\begin{array}{l}\text { Cruz et al. / } \\
(2017) \\
\text { LILACS }\end{array}$ & $\begin{array}{l}\text { Este estudo objetivou } \\
\text { compreender as } \\
\text { representações sociais de } \\
\text { profissionais } \\
\text { da saúde sobre } \\
\text { a violência contra a } \\
\text { mulher e } \\
\text { os homens autores. }\end{array}$ & $\begin{array}{l}\text { Foram entrevistados } 25 \\
\text { profissionais dos três níveis } \\
\text { de atenção à saúde a partir de } \\
\text { um roteiro } \\
\text { de entrevista semiestruturado. } \\
\text { Os dados foram tratados pela } \\
\text { análise de conteúdo temática } \\
\text { e pelo software Iramuteq. }\end{array}$ & $\begin{array}{lcr}\text { Apontaram } & \text { a representação } \\
\text { da violência contra a mulher } \\
\text { objetivada na violência física e } \\
\text { ancorada na agressão; e do homem } \\
\text { autor dessa violência objetivado na } \\
\text { figura do covarde. As práticas } \\
\text { profissionais relacionadas a } \\
\text { episódios de violência contra a } \\
\text { mulher ainda são incipientes. }\end{array}$ & $\begin{array}{l}\text { Destaca-se } \\
\text { necessidade de investir } \\
\text { em processos } \\
\text { de capacitação dos } \\
\text { profissionais para } \\
\text { trabalharem mais } \\
\text { assertivamente com a } \\
\text { temática. (AU) }\end{array}$ \\
\hline $\begin{array}{l}\text { Barros et } \\
\text { al. / (2017) } \\
\text { / PUBMED }\end{array}$ & $\begin{array}{l}\text { Analisar as violências } \\
\text { não fatais sofridas e } \\
\text { praticadas por homens e } \\
\text { mulheres adultos, em } \\
\text { situação de parceria } \\
\text { íntima. }\end{array}$ & $\begin{array}{l}\text { Os sujeitos da pesquisa foram } \\
\text { mulheres entre } 15 \text { a } 49 \text { anos e } \\
\text { homens entre } 18 \text { a } 60 \text { anos, } \\
\text { entrevistados } \\
\text { aplicação de questionário } \\
\text { face a face. A seleção } \\
\text { amostral foi do tipo } \\
\text { consecutivo, captando-se os } \\
\text { participantes por } \\
\text { ordem de chegada ao serviço. } \\
\text { Evitou-se o estudo em casais. } \\
\text { Comparou-se as situações } \\
\text { sofridas pelas mulheres } \\
\text { segundo seus relatos. } \\
\text { Também as situações que os } \\
\text { homens, segundo seus } \\
\text { relatos, praticam contra as }\end{array}$ & $\begin{array}{l}\text { A vitimização foi maior entre as } \\
\text { mulheres, independentemente do } \\
\text { tipo de violência, quando perpetrada } \\
\text { por parceiro íntimo. A percepção da } \\
\text { violência foi baixa em ambos os } \\
\text { sexos; entretanto, mulheres } \\
\text { relataram mais } \\
\text { episódios de múltiplas } \\
\text { recorrências de quaisquer violências } \\
\text { e de violência sexual sofrida do que } \\
\text { os homens reconheceram que } \\
\text { perpetraram. }\end{array}$ & $\begin{array}{l}\text { O estudo em seu todo } \\
\text { mostra importantes } \\
\text { diferenças de gênero, } \\
\text { quer quanto às } \\
\text { prevalências das } \\
\text { violências, quer } \\
\text { quanto à percepção } \\
\text { dessas situações. }\end{array}$ \\
\hline
\end{tabular}




\begin{tabular}{|c|c|c|c|c|}
\hline & & $\begin{array}{l}\text { mulheres, suas parceiras } \\
\text { íntimas ou ex-parceiras. }\end{array}$ & & \\
\hline $\begin{array}{l}\text { Andrade et } \\
\text { al./ (2016) / } \\
\text { REDALCY }\end{array}$ & $\begin{array}{l}\text { Analisar os casos } \\
\text { notificados de violências } \\
\text { contra a mulher adulta no } \\
\text { Estado de Minas Gerais, } \\
\text { Brasil, por meio do } \\
\text { SINAN, com o intuito de } \\
\text { caracterizar as vítimas e } \\
\text { as situações de abuso, } \\
\text { calcular indicadores de } \\
\text { morbimortalidade } \\
\text { avaliar a qualidade da } \\
\text { informação }\end{array}$ & $\begin{array}{l}\text { Os dados populacionais } \\
\text { necessários para os cálculos } \\
\text { dos indicadores de } \\
\text { morbimortalidade foram } \\
\text { provenientes do Instituto } \\
\text { Brasileiro de Geografia e } \\
\text { Estatística (IBGE), obtidos } \\
\text { no site do Departamento de } \\
\text { Informática do SUS } \\
\text { (DATASUS). Entre os anos } \\
\text { de 2011 e 2012. }\end{array}$ & $\begin{array}{l}\text { Houve aumento de } 41 \% \text { nas } \\
\text { notificações entre os dois anos } \\
\text { analisados. A mortalidade se } \\
\text { destacou nas vítimas com } 30-39 \\
\text { anos, a letalidade acima de } 80 \text { anos, } \\
\text { maior incidência para violência } \\
\text { física, entre } 20-29 \text { anos. }\end{array}$ & $\begin{array}{l}\text { A violência contra a } \\
\text { mulher adulta foi } \\
\text { predominante na faixa } \\
\text { jovem, entre } 20 \text { e } 39 \\
\text { anos, cor da pele } \\
\text { branca ou parda, } \\
\text { casadas ou em união } \\
\text { estável, sendo o } \\
\text { agressor na maioria } \\
\text { das vezes o cônjuge. A } \\
\text { violência em geral se } \\
\text { deu na própria } \\
\text { residência da vítima e } \\
\text { na maioria dos casos a } \\
\text { evolução r dos } \\
\text { atendimentos nos } \\
\text { serviços de saúde foi } \\
\text { para alta. }\end{array}$ \\
\hline
\end{tabular}

Fonte: dados da Pesquisa, 2020.

Apesar da grande visibilidade midiática sobre a violência de gênero e da criação da lei Maria da Penha, a qual colabora com o enfrentamento à violência contra a mulher, ainda é possível observar altos índices desse tipo de violência. Esse cenário desastroso tem como consequência a geração de danos à saúde feminina. O estudo de Andrade et al (2016), mostra que a incidência da violência contra a mulher é alta, mais que as modificações de violência aumentaram cerca de $41 \%$ entre 2011 e 2012, na qual pode-se presumir uma maior sensibilidade à identificação dos casos nos serviços de saúde. A maioria das mulheres era branca, 20 a 29 anos, casada, agredida fisicamente na sua residência, por meio de força corporal, na cabeça. Houve aumento de $41 \%$ nas notificações entre os dois anos analisados.

A violência de gênero vem se tornando um grave problema de saúde pública, o que gera consequências significativas no que se refere à saúde da vítima, seja ela física, mental ou psicológica. As mulheres, ao sofrerem as agressões, procuram, em muitos casos, ajuda nos serviços de saúde próximos a suas residências, os quais são representados pela Estratégia de Saúde da Família (ESF), mesmo que esse espaço não seja preparado e competente o suficiente de modo a acolher esse tipo de situação. Isso é grave, pois muitos profissionais de saúde demonstraram ampla dificuldade em, por exemplo, questionar as mulheres sobre a situação de violência e sua notificação (Martins et al, 2018).

Souza e Rezende (2018) salientam que apesar da alta prevalência, a violência contra a mulher ainda é pouco identificada nos serviços de saúde, o que acarreta um problema na 
efetivação das políticas de enfrentamento da violência e uma fragilidade no que se refere aos atendimentos prestados a essas mulheres. Isso acaba constituindo um sério problema que dificulta a plena efetivação e execução de políticas públicas voltadas ao combate à violência contra a mulher, visto que há empecilhos no que se diz respeito a falhas na metodologia utilizada por profissionais de saúde no atendimento a essas vítimas.

De acordo com Santos et al (2018), estudos realizados afirmam que a atenção primária à saúde enfrenta desafios e dilemas para a construção da atenção integral nos casos de violência contra a mulher, nas quais se destacam a falta de conhecimento técnico dos profissionais de saúde e a ausência de materiais para um adequado acolhimento, encaminhamento e continuidade da assistência a essas vítimas. Em alguns casos, inclusive, foi relatado que houve aceitação da violência contra a mulher como algo justificável em que a culpa é da própria mulher, o que constitui um pensamento misógino e bastante ultrapassado.

Para Souza e Cintra (2018), essas dificuldades dos profissionais de saúde para lidar com as vítimas de violência estão ligadas à sua formação, a qual tradicionalmente segue o modelo tecnicista, que impede o envolvimento e a correlação da realidade dos fatos Nesse patamar, conclui-se que o grande empecilho no enfrentamento à violência contra a mulher provém justamente dos profissionais de saúde, o que inclui, inclusive, questões de conflitos éticos e morais que acabam por fazer com que a própria vítima se enxergue como culpada e responsável pelo quadro de violência que sofreu, o que é bastante grave e deve, dessa forma, ser combatido.

Cruz, Espindula e Trindade (2017) salientam que o motivo que favorece esses episódios violentos é a justificativa social dos costumes machistas. Isso remete a um cenário no qual o gênero masculino é, na maioria das vezes, cotado até pelos profissionais de saúde como ser autoritário e, durante a prestação dos serviços, estão mais preocupados com os agravos do que com a prevenção ou denúncia do agressor. Algo que esse estudo demonstrou é que a violência contra a mulher é focada na violência física e é pautada na agressão, enquanto a imagem do homem que é autor do crime é centrada na figura de covarde. Nesse sentido, nota-se a importância, mais uma vez, de se capacitar os profissionais de saúde de modo a lidar da maneira correta ao se depararem com casos de agressões contra as mulheres, o que pode ser feito a partir da capacitação desse corpo de funcionários de maneira específica e pontual. 
Em contrapartida, Silva, Padoin e Vianna (2015), afirma que a prática assistencial nesses casos é apenas técnica e que não há pratica de reconhecimento da violência e nem intervenção imediata, no que diz respeito, por exemplo, à orientação e ao incentivo à denúncia. O que foi apontado como sendo causador/motivador da violência contra a mulher foi uma relação de hierarquia construída em relação ao papel do homem e ao papel da mulher, em que esta é submissa ao seu companheiro, "justificando", dessa forma, o porquê de os homens se sentirem no direito de agredirem suas companheiras.

De acordo com Oliveira e Fonseca (2015), essas falhas assistenciais por meio dos profissionais de saúde devem passar por transformações a fim de colocar em vigor a prática do reconhecimento e enfrentamento das necessidades em saúde das mulheres, visto que, não raras vezes, os profisssionais de saúde não conseguem estabelecer uma relação com as vítimas de violência de modo a criar um ambiente propício para que elas possam, por exemplo, desabafar em relação aos episódios de violência sofridos.

Já Barros e Shraiber (2017) mostram que a percepção de violência precisa passar por mudanças frente a atenção básica de saúde, para que as vítimas sejam bem acompanhadas, além da percepção dessas situações ajudarem a vítima no enfrentamento do problema. Essa problemática é abordada ao se considerar que não são muitos os gestores de serviços públicos que de fato compreendem o enfrentamento da violência contra a mulher como algo inerente ao exercício de sua função, além do que, em muitos casos, esses gestores sequer conhecem a legislação e as normas relacionadas a esse enfrentamento. Nesse intuito, percebe-se a necessidade em capacitar mais as pessoas envolvidas no combate à violência contra as mulheres.

\section{Considerações Finais}

Com base nos estudos realizados, foi possível observar que a violência de gênero está diretamente relacionada às condições desfavoráveis à saúde da mulher. No intuito em que se compreende as queixas das usuárias e nos casos em que elas são devidamente assistidas pelos serviços de saúde, conclui-se que é possível prevenir e minimizar os danos da violência.

Nesse sentido, nota-se a grande importância do papel dos profissionais de saúde no que diz respeito à identificação, acolhimento e seguimento das mulheres vítimas de violência nos serviços de saúde. Sugere-se que novos estudos sejam realizados para 
comprovar a importância dos profissionais de saúde frente a essa problemática, bem como a implementação de políticas públicas que auxiliem esses profissionais em suas condutas para uma melhor assistência a essas vítimas.

\section{Referências}

Albuquerque, Josefa Barros Cavalcanti de et al. (2013). Violência doméstica: características sociodemográficas de mulheres cadastradas em uma Unidade de Saúde da Família. Revista Eletrônica de Enfermagem, [s.1.], v. 15, n. 2, p.382-90, 30 jun. Universidade Federal de Goias. http://dx.doi.org/10.5216/ree.v15i2.18941.

Andrade, Júlia de Oliveira et al. (2016). Indicadores da violência contra a mulher provenientes das notificações dos serviços de saúde Minas Gerais- Brasil. Texto contexto enfermagem. V.25, n.3, p.1-9.

Barros, Claudia Renata dos Santos; Schraiber, Lilia Blima (2017). Violência por parceiro íntimo relatada por mulheres e homens usuários de unidades de saúde. Revista saúde pública. V.51, n.7.

Barros, Érika Neves de et al. (2016). Prevalência e fatores associados à violência por parceiro íntimo em mulheres de uma comunidade em Recife/Pernambuco. Brasil. Ciênc. saúde colet. vol.21, n.2, pp.591-598. http://dx.doi.org/10.1590/141381232015212.10672015

Carmo, Michelly Eustáquia do, \& Guizardi, Francini Lube. (2018). O conceito de vulnerabilidade e seus sentidos para as políticas públicas de saúde e assistência social. Cadernos de Saúde Pública,34(3), e00101417. https://doi.org/10.1590/0102$311 \times 00101417)$.

Cruz, Suzyelaine Tamarindo Marques da; Espindula, Daniel Henrique Pereira; Trindade, Zeidi Araújo (2017). Violência de Gênero e seus autores: Representações dos profissionais da saúde. Psico-USF. V. 22, n.3, p.555-567.

Duarte, Maiara Cardoso et al. (2015). Gênero e violência contra a mulher na literatura de enfermagem: uma revisão. Revista Brasileira de Enfermagem, [s.1.], v. 68, n. 2, p.325332, abr. FapUNIFESP (SciELO). http://dx.doi.org/10.1590/0034-7167.2015680220i

Kronbauer, José Fernando Dresch; Meneguel, Stela Nazareth. (2005). Perfil da violência de gênero perpetrada por companheiro: José Fernando Dresch Kronbauer e Stela Nazareth Meneghel. Revista de Saúde Pública, São Leopoldo Rs, v. 5, n. 39, p.695-701.

Martins, Lidiane de Cassia Amaral et al. (2018). Violência de gênero: conhecimento e conduta dos profissionais da estratégia saúde da família. Revista gaúcha enfermagem. V.39, n.1. 
Oliveira, Rebeca Nunes Guedes de; Fonseca, Rosa Maria Godoy Serpa da. (2015). Necessidades em saúde: a interface entre o discurso de profissionais de saúde e mulheres vitimizadas. Revista latino-americana de enfermagem. V. 23, n.2, p. 299-306.

Santos, Walquíria Jesusmara dos et al. (2018). Violência doméstica contra a mulher perpetrada por parceiro íntimo: representações sociais dos profissionais da atenção primária a saúde. BDENF- Enfermagem. V.10, n.3, p.770-777.

Silva, Ethel Bastos da; Padoin, Stella Maris de Mello; Vianna, Lucila Amaral Carneiro. Violência contra a mulher e a prática assistencial na percepção dos profissionais de saúde (2015). Rede de revistas científicas da América Latina y el caribe. V. 24, n.1, p.229237.

Souza, Angela Alves Correia de; Cintra, Raquel Barbosa (2018). Conflitos éticos e limitações do atendimento médico à mulher vítima de violência de gênero. Revista bioética. V.26, n.1, p.77-86.

Souza, Tatiana Machiavelli Carmo; Rezende, Fernanda Ferreira (2018). Violência contra mulher: concepções e práticas de profissionais de serviços públicos. Estudo interdisciplinar psicologia. V.9, n.1, p.23-38.

Terra, Maria Fernanda; D’Oliveira, Ana Flávia Pires Lucas; Schraiber, Lilia Blima (2015). Medo e vergonha como barreiras para superar a violência doméstica de gênero. Athenea Digital. Revista de Pensamiento e Investigación Social, [s.1.], v. 15, n. 3, p.109-125, 3 nov. Universitat Autonoma de Barcelona. http://dx.doi.org/10.5565/rev/athenea.1538.

\section{How to cite this article (APA format):}

Romão, Lina Maria Vidal; Coelho, José Leonardo Gomes; Feitosa, Pedro Walisson Gomes; Melo, Karine Silva; Sousa, Carmelita Maria Silva; Miranda, Thiago Adolfo Sobreira; Saraiva, Emanuela Machado Silva; Neves, Samya de Araújo; Santana, Willma José de (2020). Approach to Women's Health in Social Vulnerability Situations: An Integrative Review. Am. In. Mult. J.,Jul to Oct. (9) 5, 1-11.

Received: 06/17/2020

Accepted: 07/15/2020 